\title{
Bridging the Gap Between Discourse Analysis and Language Classroom Practice
}

\author{
Maha H. Alsoraihi ${ }^{1}$ \\ ${ }^{1}$ College of Languages, Princess Nourah Bint Abdulrahman University, Riyadh, Saudi Arabia \\ Correspondence: Maha H. Alsoraihi, College of Languages, Princess Nourah Bint Abdulrahman University, \\ Riyadh, Saudi Arabia.
}

Received: May 23, 2019 Accepted: July 10, 2019 Online Published: July 12, 2019

doi: 10.5539/elt.v12n8p79 URL: https://doi.org/10.5539/elt.v12n8p79

\begin{abstract}
This paper deals with the emergence of discourse analysis (DA), its significance and its application in the classroom environments. It also sheds light on (DA) dimensions and how its relevance to English language teaching (ELT) will enhance the quality of teaching/learning a language. This research paper supports the fact that language cannot be learned or taught in isolation. Effective language learning/teaching requires learners to be engaged in actual/social contexts in order to apply their knowledge and skills for achieving a successful communication which is the ultimate goal of learning a language. This paper discusses various associated applications of discourse analysis in language classrooms in an attempt improve the quality of language teaching/learning techniques and outcomes. The researcher also reviews the most prominent challenges that hinder the effective implementation of this approach and provide certain solutions that can be used in order to overcome these challenges. This paper assumes that learners who focus on relating linguistic knowledge to social and cultural contexts will demonstrate high levels of communicative performance and self-confidence.
\end{abstract}

Keywords: discourse analysis, language teaching, communication, competence/performance, contexts, social factors, sociolinguistics, language learning, classroom practice

\section{Introduction}

Communication within different communities is an essential tool that signifies the implementation of any language. Communication helps individuals understand and interact with each other in daily life situations; it also helps in exchanging ideas and information among them; to convey these messages, individuals mainly depend on language and the linguistic richness they already possess.

The success of learning a language heavily depends on communication and interactions taken place among students or occurred between the teacher and his/her learners in the classroom, which is considered as a must in foreign language learning, the reason for that might be attributed to their roles in contextualizing learning experiences (Domalewska, 2015).

Accordingly, language can be regarded as the main method of communication among members within varied communities at the global level. Language is used to translate the culture of different societies to reflect their traditions and values and as a result, it can be seen as a mean for global understanding (Sirbu, 2015). In other words, one can say that languages can be considered as the main engine for effective communication (Philomina, 2015).

The communicative approach and its emphasis on practical communicative activities in language learning and teaching has led to the emergence of a genuine approach for studying both written and spoken language known as discourse analysis (Chambers, 2007).

In addition, the last few decades have witnessed a radical shift from concentration on the sentence and its components to the emphasis on the context in which language is used. This also paves the way for the emergence of "Discourse Analysis". This new approach and its communicative nature have managed to attract researchers' attention and as a result, many studies have been dedicated to investigate the nature of the new approach, its methods, and scope of applications in different fields (Drid, 2010).

Discourse analysis has its roots in many disciplines where language occupies a significant position as a tool for human communication (Drid, 2010). In consistent with the idea mentioned above, one can say that discourse 
analysis has succeeded in becoming a significant field of research at the level of different disciplines, including but not limited to sociology, psychology, sociolinguistics, and applied linguistics (Chambers, 2007; Qomi, 2019).

In other words, discourse analysis can be regarded as a diverse area of research used to refer to the linguistic analysis of speech through shedding the light on the language's structure and functions and its unique linguistic characteristics (Rashidi \& Rafieerad, 2010).

Discourse has structural and functional nature. One can depend on these two perspectives to show how language is used within the scope of social context. Discourse has certain features that embedded in the field of discourse, the significance of these features stems from the fact that scholars' and linguists' knowledge of them makes the analysis easier for scholars, these characteristics and features can be represented in conversation, discourse participants, opening and closing of discourse, turn-taking, selecting the next speaker, overlapping, topic negotiation, speech errors, repair mechanism, talk initiation, role sharing, elicitation in talk and adjacency pairs (Osoba \& Sobola, 2014).

The main theme in discourse analysis is the study of the unique relationship between language and the context in which it is used. This approach has emerged out of works in different disciplines including linguistics, sociology, psychology, and anthropology in the period between 1960s and early 1970s. The period 1980s has become a milestone in the history discourse analysis. In that period an academic journal "Text" was founded which made discourse analysis an academic field. Van Dijk has edited and published a book entitled "Handbook of Discourse Analysis" In 1985, through which discourse analysis has become an independent discipline of study (Jiang, 2012).

Discourse Analysis has concentrated on both spoken and written texts by identifying the relationship between the linguistic form and its functions, especially while taking into account that spoken and written discourses have varied social uses and as a result have different communicative functions (Tabrizi, Gupta, \& Saxena, 2014).

Discourse analysts are concerned with the language choices people make to achieve their social goals, where cultural ideologies reproduced in the discourse occupy prominent positions in their analyses. Accordingly, discourse analysis can be used as a structural tool to understand how texts are organized and as an ethnographic tool to better grasp cultural dynamics (Wennerstrom, 2003). In consistent with the idea mentioned above, Osoba and Sobola (2014) have confirmed that discourse analysts pay great attention to the language being used in social context by shedding the light on its organization and the different processes involved in the encoding and decoding processes of its meaning without concentrating on the formal properties of a language.

Tabrizi et al. (2014) have confirmed that according to discourse analysts, discourse can be used to reflect the nature and significance of the communicative purposes through depending on communication as the main medium of language used to convey much information in different fields. In other words, discourse analysis is not confined to a specific discipline, as it can be applied to any context or situation and as a result, a photo, a song, or a video can be subject to linguistic examination (Martínez, 2014).

Worthy here to mention that although discourse analysis does not provide a comprehensive framework through which we can understand the communication process, it enables us as speakers to understand and interpret varied motivations behind written or spoken discourses (Berrocal, Villegas, \& Barquero, 2016). Discourse itself involves several processes. Investigating the construction of these processes requires analytical tools derived from psychology, linguistics, sociology, philosophy, and anthropology (Drid, 2010).

\section{Methodology}

\subsection{Data \& Materials}

The purpose of the current study is to show the importance of relating discourse analysis to language learning practice. Basically, teaching a language means teaching to communicate. For example, in teaching phonology, morphology, syntax, etc., would be meaningless without using such knowledge in social contexts. In other words, meaning in discourse practice can be learned effectively through the interaction between the actual linguistic meaning and its social context.

The best method to adopt for achieving the purpose of the study is observation and recording L2 learners' performance over a long period of time. This method is considered as an effective investigating method for achieving a better understanding of a phenomenon based on methodological means of inquiry that address social factors concerning human performance. The researcher, who is very interested in monitoring L2 performance, is the main instrument of collecting and analyzing the recorded data. 
The study is conducted on one of the researcher's classes (Syntax) at College of Languages at PNU, monitoring L2 performance in learning English sentence structures over a period of time ranging to cover a whole academic year. The main goal is to introduce linguistic rules together with sociolinguistic knowledge concerning the appropriateness of using language in various social contexts such as learning how to ask for favors, giving/accepting invitations, compliments, apologizing, etc., In other words, L2 learners have to focus on how "situational factors such as the cultural context and the setting of a speech event affect the choice of what should be said" (Brown, 2000, p. 220).

The recorded data of L2 learners' performance have been analyzed by the researcher to find out how discourse analysis practice will result in a successful communication in a way that will reduce L2 learners' anxiety and increase their self-confidence. Krashen (1987) called it "Affective filter" which includes motivation, self-confidence, and anxiety. Further, the collected data will focus on aspects of sociolinguistic competence such as politeness, formality, cultural aspects, etc. (Brown, 2000). Other nonverbal communication which deals with body language, gestures, eye contact will also be considered. The importance of the current study stems from the fact that it is difficult for L2 learners to notice and understand such sociolinguistic codes of communication unless these contexts and cultural aspects are directly taught (Bennett, 1998). It is assumed that L2 learners participating in this study will demonstrate a higher level of language proficiency and self-confidence compared to others who have been introduced to the same courses without relating the linguistic knowledge to social and cultural contexts.

\subsection{Definition of Discourse Analysis}

If we consider the theoretical framework, we can find out that there are many definitions of discourse analysis; these definitions can be reviewed as in the following order:

Fairclough (1995) has defined discourse analysis as the analysis of different texts within the scope of sociocultural practice. This analysis in fact "requires attention to textual form, structure and organization at all levels; phonological, grammatical, lexical (vocabulary) and higher levels of textual organization in terms of exchange systems (the distribution of speaking turns), structures of argumentation, and generic (activity type) structures" (p. 7).

Some researchers have tried to provide a definition of discourse analysis by linking it to communication. Bavelas, Kenwood \& Phillips (2000) have defined discourse analysis as "the systematic study of naturally occurring (not hypothetical) communication in the broadest sense, at the level of meaning (rather than as physical acts or features" (p. 102).

Wennerstrom (2003) has provided a definition of discourse analysis through concentrating on the context in which it is used. This definition can be represented in "the study of naturally occurring language in the context in which it is used" (p. 6).

In consistent with the definition mentioned above, Rymes (2008) has defined discourse analysis as "the study of how language-in-use is affected by the context of its use. In the classroom, context can range from the talk within a lesson, to a student's entire lifetime of socialization, to the history of the institution of schooling" (p. 12).

Also, Gee (2011) has provided a definition similar to definitions mentioned above, he has defined discourse analysis as "the study of language-in-use. Better put, it is the study of language at use in the world, not just to say things, but to do things" (p. ix).

Hai (2004) has defined discourse analysis as "the analysis of language beyond the sentence. This contrasts with types of analysis which are mainly concerned with grammar, word meanings, sounds, and rules for making meanings" (p. 37).

Mit'ib (2010) has defined discourse analysis as the "methodological tool, which easily lends itself to the investigation of the functional properties of talk, developmental process as well as discrimination by identifying social attitudes and ideologies responsible for observed linguistic patterns" (p. 39).

Rashidi and Rafieerad (2010) have linked discourse analysis to the language in use. They have defined it as "the examination of language use by members of a speech community. It involves looking at both language form and language functions and includes the study of both spoken interaction and written texts. It identifies linguistic features that characterize different genres as well as social and cultural factors that aid us in our interpretation and understanding of different texts and types of talk" (p. 95).

Other researchers have tried to make a connection between discourse analysis and language functions and forms. 
Jiang (2012) has defined discourse analysis as the study of the relationship between language and its context through shedding the light on language form and functions, spoken interaction and written texts. According to this definition, discourse analysis "identifies linguistic features that characterize different genres as well as social and cultural factors that aid in our interpretation and understanding of different texts and types of talk" (p. 2146).

Alsaawi (2016) has defined discourse analysis as "the study of language in either spoken or written form" (p. 244).

\subsection{Significance of Discourse Analysis to Language Teaching}

In the early 1970s, the communicative approach to language teaching has been emerged, which is considered as a radical shift in the history of language teaching; the reason for that might be attributed to its capacity in making people aware of the need to focus on language communicative features, this in fact has paved the way for the emergence of what has been called as "language for communication" and "language as communication". Accordingly, the objective of language teaching is to enable learners to be able to communicate, even at a limited scope, using the target language in order to give learners real opportunities to experience and practice communication. Here, discourse analysis has emerged as an essential component in teaching language through the communicative approach (Olshtain \& Celce-Murcia, 2001).

Discourse analysis pays great attention to language forms and functions in social interactions to improve language acquisition by analyzing how native and foreign speakers use language within the social context. In other words, discourse analysis concentrates on details of speech used by people in order to convey the social meaning using the components of language represented in morphology, syntax, phonetics, and phonology (Berrocal et al., 2016).

Many researchers think that discourse analysis and pragmatics are essential to language teaching and learning. They also play significant roles in facilitating human communication. Discourse analysis is concerned with intended meaning and sequential relationships transmitted within context, while pragmatics is concerned with the interpreted meaning from linguistic processing and social interaction. In other words, one can say that for the language teaching process to go in harmony with discourse analysis, it must focus on strategies that facilitate learner communicative production and strategies of interpretation (Olshtain \& Celce-Murcia, 2001).

Danesh, Aghagolzadeh and Maftoon (2016) have shown that there was an improvement on reading comprehension after students become aware of critical discourse analysis and its elements, as they became more enthusiastic, and learned activities more effectively. In other words, one can say that critical discourse analysis represents a critical approach in teaching EFL. It supports learners developing their English language competence. Discourse analysts are concerned with how to interpret the relationship between the different units of the language in an attempt to reach a comprehensive framework of meaning, for example they may analyze utterances grammatical forms to understand and interpret meanings expressed through discourse. For example, the interrogative form is used to elicit information, it can also be used to express expectations, make requests and suggestions (Hai, 2004).

\section{Discussion \& Recommendations}

Introducing syntactic rules to language learners together with the sociolinguistic knowledge not only increases students' level of involvement and interaction but also bridges the gap between the abstract linguistic knowledge of the language and using it in appropriate situations. For example, in introducing the abstract structure of adjective phrases to L2 learners, another area has been discussed by the teacher asking the students to brainstorm adjectives used to give compliments in various social and cultural contexts. Another cultural perspective has also been discussed which is the one relates to how compliments made recipents feel as a practice of showing appreciation. The same case is with other abstract linguistic structures such as apologizing and showing responsibility for offending others. Learners need to know that, from a cultural perspective, saying "I am sorry", is not only used to apologize for hurting others. English people, for example, tend to apologize even when nothing wrong is done. They tend to apologize even for asking clarification, restationg what others have been said, or interrupting other speakers. Students participating in this study have been introduced to various social and cultural sitautions while learning abstract linguistic knowledge of the target language. It has been clearly noticed by the researcher that such vivid situations have noticeably enhanced students' communicative performance, increased their self-confidence, and most important, decreased their level of anxiety when engaging in classroom language practice.

\subsection{Discourse Analysis in Language Classroom}

It is well known that discourse analysis in the classroom is the direct application of sociolinguistic approach to 
daily practice of teachers. Classroom discourse analysis develops teachers' and students' meta-discursive reflection, which are considered as critical in multilingual education at the level of current globalized educational systems. In addition, discourse analysis taken place in the classroom is considered as an ideal mechanism to understand repertoires circulating in a classroom (Rymes, 2010).

If we talk about the use of discourse analysis in the classroom, we can notice that it enables us to understand the complex relationship between students and teachers' interactions, and its effects on the learning process taken place in the classroom environment (Woodward-Kron \& Remedios, 2007).

Classroom discourse analysis is a crucial element of classroom practice. It helps us understand to what extent can teachers employ the language in the classroom (Qomi, 2019). It also provides us with valuable information concerned with language analysis and its reflection on culture awareness (Martínez, 2012). Discourse analysis taken place in the classroom enables both teachers and students understand the different contexts and enable them to identify language corresponding functionality (Rymes, 2008).

Classroom discourse analysis turns to critical classroom discourse analysis when its effect taken into consideration by classroom researchers while conducting their analyses (Rymes, 2008). Rymes (2010) has stated that for a novice classroom discourse analyst who wished to conduct discourse analyses, the following steps are recommended:

(1) Spend some time identifying the different speech events in the classroom. Identify either a focal event or relevant comparative events.

(2) Record the focal event and begin to characterize the language in that event. To do so, you will not need to fully transcribe the talk. Start by listening to the tape and, using the categories listed in Figure 19.1 as an initial guide, identify instances of talk that make this event distinctive. For example, listen for multilingualism and its effects; listen for the use of names and nicknames; listen for greetings, brand names, praise or politeness tokens. Begin to characterize this event's normative language patterns. Transcribe those instances of talk that are most relevant to this characterization.

(3) Look for variation in language use within that event or across comparison events. You may want to investigate the participation of one 'disruptive' student, as Griffi n did. Alternatively, like Philips, you may want to investigate how certain students participate differently across different events (pp. 542-543).

If we talk about discourse-oriented approach to grammar, we can notice that it places greater emphasis on the texts with grammatical points where the grammatical rules can be explained. Here, students need to know the repertoire of grammatical rules and the conditioning rule of discourse and context to make appropriate choices. At the level of teaching and learning of vocabulary, we can notice that the role of discourse cannot be denied as vocabulary cannot be taught out of its context to convey the meaning of words rather than reflecting the semantic content. If we talk about the discourse-oriented reading, we can find that it allows learners to interact with texts by involving them in making choices with respect to the reading text to become independent readers (Olshtain \& Celce-Murcia, 2001). In consistent with the idea mentioned above, Dar, Rahimi and Shams (2010) have revealed that about $99 \%$ of students were more motivated and more interested in reading the texts after becoming aware of the critical discourse analysis.

Worthy here to mention that, the process of teaching and learning English in the classroom is a very complicated process; this might be attributed to the fact that it involves various factors related to teachers, students, and the classroom environment. Because of its complicated nature, it has succeeded in attracting the attention of scholars from different disciplines, such as sociology, pedagogy, linguistics, and psychology. In a similar way, classroom discourse has become one of the hot topics being discussed by researchers at the level of classroom research and second language acquisition as it highlights the mechanism through which teachers and students communicate and interact with each other in the classroom environment and identifies ways through which teachers and students communicate with each other in the daily teaching practice (Qomi, 2019).

In the second half of the twentieth century, the communicative approach has also been used in the teaching of Languages for Specific Purposes as a result of developments in discourse analysis researches (Chambers, 2007).

Discourse analysis can also be used by classroom teachers as a powerful tool to create new forms of identities and empower students in the current globalizing world. Teachers can use discourse analysis to develop social interactions in the classroom environments. Discourse analysis can be seen as a tool for achieving change in classroom practice where traditional roles of teachers and students have been shifted to accommodate their new roles in classroom discourse. In other words, discourse analysis can be incorporated in teacher education courses for better understanding their new roles in the light of discourse analysis skills and competencies (Rumenapp, 
2016).

At the level of teaching and learning of English as a foreign language, discourse analysis provides techniques to acquire linguistic knowledge and competences in contexts where English is not the mother tongue and as a result it doesn't be used frequently in social life. It allows the use of inquiries that are considered as crucial in linguistic development and facilitates understanding the social appropriations of English as a foreign language to enhance the process of language interaction (Escobar \& Castañeda-Peña, 2015).

Tang (2008) has stated that the study of discourse analysis and the employment of it in different contexts can result in:
* Language awareness enhancement.
* Critical mindset.
* Greater understanding of everyday contexts,
* Better understanding of things taught about language in the classroom.
* Developing the mechanism used in teaching English language.
* Improvement of communication sensitivity.

Despite the advantages mentioned above, the biggest obstacle that hinder the effective implementation of the communicative approach in the classroom environments can be investigated from theoretical and practical levels such as lack of proper knowledge in discourse analysis provided to language teachers, curriculum developers and textbook designers. Although language teaching professionals receive training in grammar, phonetics, and language skills, a few programs have been dedicated to discourse analysis. In addition, teachers need to have not only good knowledge in discourse analysis and cultural differences, but also awareness of discourse and students' cultural features. Taking into account the multicultural nature of language classrooms nowadays, Language teachers need training in cross-cultural communication (Olshtain \& Celce-Murcia, 2001).

Although many schools have adopted the communicative approach in teaching and learning, this approach has not yet achieved its meaningful results to language teaching and learning; this might be attributed to the fact that teachers have low linguistic competencies and language teachers still use the traditional structural approach, which deals with the language as an autonomous system rather than a means of communication. In other words, one can say that it may take many years before we can see the meaningful effects of this approach in the language classroom. For this process to be effective, discourse analysis specialists must cooperate with curricula designers in preparing new language content that focuses on communication and developing programs being provided to pre-service students to improve their linguistic competencies and enable them to teach using the new approach (Cots, 1996).

Berrocal et al. (2016) have provided certain recommendations to teach students to use spoken discourse more effectively in the classroom, these recommendations can be reviewed as following:

$\rightarrow$ Enable learners to reflect upon discourse and communication: By looking at authentic language used in real or casual environments, students learn how to appreciate and be aware of the discourse patterns associated within a particular context or situation.

$\rightarrow$ Implement self-recording activities: More practical activities that require self-recording exercises are the first step in introducing discourse analysis awareness. Include activities in which students are able to record and transcribe their own spontaneous speech for further analysis in order to improve communicative competence. This helps the learners to be aware of self-monitoring. Use activities that can easily be adapted to suit a variety of foreign language learning situations that meet the course functions.

$\rightarrow$ Peer analysis: Have students themselves explore their own and others' spoken interactions. Students need to have the experience of creating their own questions and interview each other. Whenever possible, they should record themselves to capture both questions and responses exactly as they were said. After that, they can transcribe their conversation. A transcript will help learners identify words, phonemes or grammar features easily in the data analysis.

$\rightarrow$ Break language down into skill areas: Ask students to break down the target language into areas such as vocabulary, grammar, and pronunciation in order to provide analysis of different features for each area. Taking a closer look at nouns, verbs, and adjectives in dialogues will help to find any common features.

$\rightarrow$ Encourage the analysis of spoken interaction, including aspects of informal talk: Through interactive activities that promote interaction, learners will be provided with a whole array of opportunities for them to 
engage in talk. Language professors are likely to notice that students produce different speech patterns in response to different communicative tasks. For instance, debates and impromptu role plays can be examples of these tasks.

$\rightarrow$ Include discourse analysis for teaching culture: Language and culture cannot be separated. Exploring the use of the target language within a particular culture will help students figure out what function intertextuality serves in light of the overall argument. For instance, students of English as a second language who develop their communicative competence within a foreign culture might find that this type of analysis is actually very enhancing due to the fact that they can compare and contrast both cultures, the one in which they are learning and the target culture.

$\rightarrow$ Use media resources to listen to and observe speakers for realistic analysis: Media tools are popular subjects of analysis for critical discourse. Working with audio and video recordings of talk and social interaction is always an accurate and authentic method to be used in and outside the classroom. For example, English professors can select videos to represent standard American and British English to analyze a short conversation or speech and then compare and contrast certain choices of verbs or vocabulary in speech (pp. 224-225).

\subsection{Dimensions of Discourse Analysis in the Classroom}

Discourse analysis is being used in classrooms to reflect ways through which teachers can build communities of learners while maintaining their leadership role in the classroom (Otten, 2010). Discourse community can be viewed as a group of people who share similar knowledge, culture, code of behavior, common language, common goal or interest and common physical environment. According to this definition, the language classroom can be considered as a unique discourse community where students and teachers share many common things. There is also an unwritten "contract" that includes obligations and commitments the group members must adhere to them. In other words, the language classroom can be considered as a discourse community where students and teachers can develop their linguistic and cultural discourse competencies (Olshtain \& Celce-Murcia, 2001). Rymes (2016) has summarized dimensions of discourse analysis as in the following dimensions:

$\checkmark$ Social context (including the entire biographical history of an individual) shapes what repertoire an individual commands. If I grew up in Mexico, chances are that Spanish is a significant part of my communicative repertoire. But social context also shapes how others value that repertoire. Even if an individual prefers to use Spanish in math class, a teacher might make rules that prohibit the use of languages other than English. To paraphrase George Orwell, some repertoires are more equal than others.

$\checkmark$ Interactional context (the moment- to- moment unfolding of an interaction) shapes which elements of an individual's repertoire emerge and how they function. For example, even if there are no official rules about which languages are allowed in our conversation, if I start speaking Spanish, whether someone chooses to respond in English or Spanish (or some other way) potentially changes the course of our conversation.

$\checkmark \quad$ An individual has varying degrees of agency to affect how certain repertoire elements become relevant in any given interaction. For example, if a student persistently uses Spanish among classroom peers, or explains to a monolingual teacher why they are using Spanish in addition to English, or even teaches the teacher a few phrases, that student may be able to construct a larger role for Spanish in that classroom (p. 21).

\subsection{Bridging the Gap Between Discourse Analysis and Language Classroom}

Language teachers should pay due attention to discourse analysis because of its positive impacts on the teaching and learning processes and its great effects on the communication process with the target language. Language teachers can use it as an evaluative method for evaluating their own teaching practices and as a valuable tool employed in classroom for enhancing the interaction process among language learners. Teachers can also play effective roles in encouraging students to employ discourse analysis in understanding the target language and the varied contexts in which it can be used (Tabrizi et al., 2014).

In educational contexts, discourse analysis has been used as a mechanism through which linguistic competence can be built in order to enable students to succeed (Shahani \& Chalak, 2017). Worthy here to mention that the employment of discourse analysis into the language classroom as an analytical technique is not an easy task as it requires reconsideration in the teaching and learning processes by focusing not on the language itself but on harnessing the language to serve many communicative purposes as well in an attempt to improve the quality of education in the current globalized economies that heavily depend on communication among individuals. In addition, employing discourse analysis into the language classroom is not an end in itself but rather, it can be regarded as a means to make the teaching and learning process more effective and develop students' communicative competences and skills represented in linguistic competencies and discourse sociolinguistic skills 
that are considered as essential in grasping and interpreting social messages embedded in the language (Cots, 1996).

As previously mentioned, discourse analysis provides learners with new skills and develop their competencies in interpreting language in its unique context whether at the level of society or culture. For the teaching process to be effective using this approach, teachers should develop their teaching practices by having a closer look on the used language in and out of the classroom, especially while taking into account that discourse analysis has the ability to motivate students to interpret information received through language every day through their different means of communication (Martínez, 2012).

\section{Conclusion}

The success of learning a language heavily depends on communication and interactions taken place among students or between them and the teacher in the classroom. The communicative approach has led to the emergence of discourse analysis that has its roots in many disciplines. The main theme in discourse analysis is the study of the unique relationship between language and the context in which it is used. It concentrates on spoken language and written texts through shedding the light on the relationship between the linguistic form and its functions. Classroom discourse analysis is a crucial element of classroom practice; it enables us to understand the complex relationship between students and teachers and provides us with valuable information related to language analysis. Although many schools have adopted the communicative approach in teaching and learning, it has not yet achieved its desired results due to problems in teacher preparation and training.

Worthy here to mention teaching and learning processes without discourse, will give less impression, as the success of teaching and learning are not only confined to the method itself, but rather it heavily depends on also the discourse used for achieving that process. In other words, on can conclude that the use of discourse in language teaching and learning will enable learners to use the language in its proper and accepted context, especially if this language is not the mother tongue of students (Muzaki, 2017).

Decision makers should take into consideration the importance of providing suitable environments for enhancing the discourse analysis approach in language teaching and learning in the classrooms. They should take into their consideration the discourse analysis approach in language teaching and learning. There is a real need to create suitable environments for interaction, and provide students with real opportunities to exercise language in a variety of situations to develop the processes of language acquisition and language development in accordance with the communicative perspective.

\section{References}

Alsaawi, A. (2016). Written Discourse Analysis and its Application in English Language Teaching. Arab World English Journal (AWEJ), 7(2), 244-254. https://doi.org/10.24093/awej/vol7no2.16

Bavelas, J. B., Kenwood, C., \& Phillips, B. (2000). Discourse Analysis. In M. Knapp, \& J. Dary (Eds.), Handbook of Interpersonal communication (3rd ed., pp. 102-109), Newbury Park, CA: Sage.

Bennett, M. J. (1998). Basic concepts of intercultural communication. Intercultural Press, Inc.

Berrocal, M. L., Villegas, V. M., \& Barquero, V. V. (2015). Bringing critical discourse analysis into the foreign language classroom: A case study of a Taiwanese learner of Spanish in Costa Rica. Revista de Lenguas Modernas, 24, 215-226.

Brown, H. D. (2000). Principles of language learning and teaching (4th ed.). California: Sann Francisco State University.

Chambers, A. (2007). Language learning as discourse analysis: Implications for the LSP learning environment. Open Edition Journals-Asp, 15(52), 1-17. https://doi.org/10.4000/asp.483

Cots, J. M. (1996). Bringing discourse analysis into the language classroom. Links \& Letters, 3, 77-101.

Danesh, A., Aghagolzadeh, F., \& Maftoon, P. (2016). The Role of Critical Discourse Analysis on Reading Comprehension Skills among Iranian EFL Learners. Intl. J. Humanities, 23(4), 47-69.

Dar, Z. K., Rahimi, A., \& Shams, M. R. (2010). Teaching Reading with a Critical Attitude: Using Critical Discourse Analysis (CDA) to Raise EFL University Students' Critical Language Awareness (CLA). International Journal of Criminology and Sociological Theory, 3(2), 457-476.

Domalewska, D. (2015). Classroom Discourse Analysis in EFL Elementary Lessons. International Journal of Languages, Literature and Linguistics, 1(1), 6-9. https://doi.org/10.7763/IJLLL.2015.V1.2

Drid, T. (2010). Discourse Analysis: Key Concepts and Perspectives. The Effect, 20-25. 
Escobar, W., \& Castañeda-Peña, H. (2015). Discourse Analysis Applied to English Language Teaching in Colombian Contexts: Theory and Methods. Bogotá: Universidad El Bosque.

Fairclough, N. (1995). Critical discourse analysis: the critical study of language. New York: Longman Group Limited.

Gee, J. P. (2011). How to do Discourse Analysis a Toolkit. Oxon: Routledge. https://doi.org/10.4324/ 9780203850992

Hai, N. T. H. (2004). The Importance of Discourse Analysis in Teaching Oral English. Teacher's Edition, 36-40.

Jiang, X. (2012). A Study of College English Classroom Discourse. Theory and Practice in Language Studies, 2(10), 2146-2152. https://doi.org/10.4304/tpls.2.10.2146-2152

Krashen, S. D. (1987). Principles and Pracice in Second Language Acquisition. London. Prentice Hall.

Martínez, D. F. (2012). Critical Learning: Critical Discourse Analysis in EFL Teaching. Journal of Language Teaching and Research, 3(2), 283-288. https://doi.org/10.4304/jltr.3.2.283-288

Martínez, D. F. (2014). Teaching and learning discourse analysis: some ideas on the use of ICTs. I Jornadas Iberoamericanas de Innovación Educativa en al ámbito de las TIC, (2014), 71-80.

Mit'ib, M. A. (2010). Discourse Analysis and English Language Teaching: A Functional Perspective. Al-Qadissiya Journal for Arts and Educational Sciences, 9(2), 39-50.

Muzaki, F. I. (2017). Teaching Discourse Analysis through Listening for ESL Learners in Indonesia: A Conceptual Review. International Journal of Language and Literature, 5(1), 99-102.

Olshtain, E., \& Celce-Murcia, M. (2001). Discourse Analysis and Language Teaching. In D. Schiffrin, D. Tannen, \& H. E. Hamilton (Eds), The Handbook of Discourse Analysis (pp. 707-724). USA: Blackwell Handbooks. https://doi.org/10.1002/9780470753460.ch37

Osoba, S., \& Sobola, E. (2014). Introduction to Discourse Analysis. In E. A. Adedun, \& Yaw Sekyi-Baidoo (Eds.), English Studies In Focus: Readings In Language And Literature. Faculty of Languages, University of Education, Winneba, Ghana.

Otten, S. (2010). Discourse Analysis and Functional Grammar in the Classroom: The summary of a mini-reading course. Research Paper, Michigan State University.

Philomina, M. J. (2015). diagnosis of reading and writing skills in primary school students. International Journal of English Language Teaching, 3(7), 1-7,

Qomi, M. A. E. (2019). EFL (English as a Foreign Language) Classroom Discourse Analysis: Focus on Teacher Talk.

Rashidi, N., \& Rafieerad, M. (2010). Analyzing Patterns of Classroom Interaction in EFL Classrooms in Iran. The Journal Of Asia TEFL, 7(3), 93-120.

Rumenapp, J. C. (2016). Analyzing discourse analysis: Teachers' views of classroom discourse and student identity. Linguistics and Education, 35, 26-36. https://doi.org/10.1016/j.linged.2016.04.002

Rymes, B. (2008). Introduction To Classroom Discourse Analysis. Classroom Discourse Analysis: A Tool for Critical Reflection. Cresskill, NJ: Hampton Press.

Rymes, B. (2008). Dimensions of Discourse and Identity. In Classroom Discourse Analysis: A Tool for Critical Reflection. Cresskill, NJ: Hampton Press.

Rymes, B. (2010). Classroom Discourse Analysis: A Focus on Communicative Repertoires. In N. H. Hornberger, \& A. Luke (Eds.), Sociolinguistics and Language Education (pp. 528-546). Great Britain: Run Press Ltd. https://doi.org/10.21832/9781847692849-021

Rymes, B. (2016). Dimensions of Discourse and Identity. Classroom Discourse Analysis A Tool for Critical Reflection (2nd ed.), New York: Routledge. https://doi.org/10.4324/9781315775630

Shahani, S., \& Chalak, A. (2017). Classroom discourse analysis as a tool for reflective practice: Focus on form approach. RALs, Special Issue, 84-89.

Sirbu, A. (2015). The Significance of Language as A Tool of Communication. Naval Academy Scientific Bulletin, XVIII(2), 405-406.

Tabrizi, A. R. N., Gupta, D., \& Saxena, M. (2014). Discourse Analysis in the ESL Classroom. Beyond Words, 2(1), 73-89. 
Tang, R. (2008). Studying discourse analysis: Does it have an impact on trainee English language teachers? ELTED, 11(2008), 27-32.

Wennerstrom, A. (2003). Discourse Analysis and Second Language Writing. Discourse Analysis in the Language Classroom (2nd ed., pp. 3-18). USA: The University of Michigan Press. https://doi.org/10.3998/ mpub. 8751

Woodward-Kron, R., \& Remedios, L. (2007). Classroom Discourse in Problem-Based Learning Classrooms in The Health Sciences. ARAL: Australian Review of Applied Linguistics, 9.1-9.18. https://doi.org/10.1075/ aral.30.1.07woo

\section{Copyrights}

Copyright for this article is retained by the author(s), with first publication rights granted to the journal.

This is an open-access article distributed under the terms and conditions of the Creative Commons Attribution license (http://creativecommons.org/licenses/by/4.0/). 